\title{
Temperature Probe Device
}

National Cancer Institute

\section{Source}

National Cancer Institute. Temperature Probe Device. NCI Thesaurus. Code C50300.

A remote sensor designed to respond to the temperature of a space, surface, or environment. 